\title{
Breastfeeding difficulties and supports and risk of postpartum depression in a cohort of women who have given birth in Calgary: a prospective cohort study
}

\author{
Kathleen H. Chaput PhD, Alberto Nettel-Aguirre PhD PStat, Richard Musto MD, Carol E. Adair PhD, \\ Suzanne C. Tough PhD
}

\section{Abstract}

Background: A link exists between breastfeeding difficulties and postpartum depression, and evidence shows that some breastfeeding promotion initiatives may increase maternal stress and contribute to risk of the condition. We conducted a prospective cohort study to determine whether breastfeeding difficulties affect the risk of postpartum depression and whether breastfeeding support modifies the relationship between breastfeeding difficulties and postpartum depression.

\begin{abstract}
Methods: Between June and October 2010, we recruited 442 women who intended to breastfeed from all maternity hospitals in Calgary within 72 hours of giving birth to full-term, singleton infants. We administered questionnaires at birth and 6 weeks and 6 months postpartum, measuring breastfeeding difficulties, exposure to breastfeeding supports and postpartum depression. We used qualitative inquiry to measure breastfeeding support experiences. Postpartum depression was defined as a score of 10 or greater on the Edinburgh Postnatal Depression Scale or a self-reported diagnosis of depression in the first 6 months postpartum.
\end{abstract}

Results: A total of 386 women (87.3\%) reported moderate to severe breastfeeding difficulties and 437 (98.9\%) received some form of breastfeeding advice, help or support. Among women with breastfeeding difficulties, those who did not report a negative breastfeeding support experience were at decreased risk of postpartum depression (risk ratio 0.36). In the final regression model a negative breastfeeding support experience was a significant effect modifier of the relationship between breastfeeding difficulties and postpartum depression.

Interpretation: The quality of breastfeeding support is important not only for breastfeeding promotion but also for maternal mental health. Educating front-line caregivers to ensure that support experiences of breastfeeding women are positive can reduce the risk of postpartum depression.

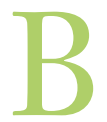

reastfeeding is globally accepted as the best infant feeding method for its economy and its immediate and long-term health benefits, including decreased risk of infection and diarrhea in the infant ${ }^{1-25}$ and reduced risk of type 2 diabetes and uterine and ovarian cancers in the mother..$^{26,27}$ Difficulty with establishing and maintaining breastfeeding in the first days of an infant's life is common; $60 \%$ to $80 \%$ of women experience problems, and $42 \%$ of all women who attempt breastfeeding (90\% of those with problems) quit within 6 weeks. ${ }^{28,29}$ Although there are several studies of suboptimal breastfeeding duration, ${ }^{6,30-32}$ breastfeeding difficulties have received insufficient attention. ${ }^{33}$ Difficulty with breastfeeding is stressful. Early postpartum stress and anxiety are known risk factors for postpartum depression. ${ }^{28,34}$ Public health initiatives designed to promote breastfeeding are widespread in North America. ${ }^{1,35}$ Both formal (health care providers) and informal (family, friends) breastfeeding supports are commonplace in Canada. There is high social awareness that breastfeeding is the "best choice," and many women report feeling strong social pressure to breastfeed. ${ }^{36}$ The combination of breastfeeding promotion and perceived social pressures may exacerbate the stress felt by women who experience breastfeeding difficulties, which may lead to poor mental health outcomes.

Postpartum depression is the primary complication of pregnancy, affecting $15 \%-20 \%$ of new mothers in developed countries. ${ }^{34,37,38}$ The condition has adverse effects on both maternal and child health, including impaired parent-

Competing interests: None declared.

This article has been peer reviewed.

Correspondence to: Kathleen Chaput, khchaput@ucalgary.ca

CMAJ Open 2016. DOI:10.9778/cmajo.20150009 
ing ability ${ }^{39,40}$ and increased risk for social and developmental delays. ${ }^{41-43}$ In Canada, women are usually identified only after the onset of depression, when negative effects are already being felt by the woman and her family. There is a need for evidence-based preventive efforts to reduce the incidence of postpartum depression. We conducted a prospective cohort study aimed at improving the understanding of the relationships between breastfeeding and postpartum depression and to increase the evidence base for the development of policy and educational interventions that will ensure women receive the most appropriate postpartum support. We hypothesized that breastfeeding difficulties increase the risk of postpartum depression and a negative experience with breastfeeding support/services modifies the relationship between breastfeeding difficulties and postpartum depression.

\section{Methods}

\section{Sample and recruitment}

We used a mixed-methods convergence design. The qualitative component of the study is described elsewhere. ${ }^{44}$ Between June and October 2010, we recruited women aged 18 years or older from the postpartum units of all 3 hospitals providing maternity care in Calgary within 72 hours of giving birth to full-term singleton infants. All women admitted to postpartum units who expressed an intention to breastfeed before delivery were informed of the study by nurses. Research assistants visited the postpartum units daily and invited all eligible women to participate. Recruitment was conducted on a rotating schedule (mornings, afternoons and evenings). After obtaining written informed consent, research assistants provided participants with instructions and study materials. Intention to breastfeed was a necessary inclusion criterion, as participants had to be at risk of having breastfeeding difficulties (study exposure). Exclusion criteria were prenatal plans to bottle feed, inability to communicate effectively in English (study resources did not support translation services) and a neonatal intensive care unit stay longer than 24 hours, as such stays place a unique stress on mothers.

\section{Data collection}

Participants completed a paper questionnaire collecting qualitative and quantitative data after the birth of their baby; at 6 weeks and 6 months they had the choice between paper and electronic formats (Appendix 1, available at www.cmajopen. ca/content/4/1/E103/suppl/DC1). Data were collected on breastfeeding, breastfeeding supports, maternal and infant demographic characteristics, pregnancy and birth information, maternal mental health and potential confounders identified in the breastfeeding and maternal mental health literature. As maternal recall of breastfeeding events is documented to be poor, ${ }^{45}$ we provided participants with a daily breastfeeding $\log$ sheet to fill out and reference when completing follow-up questionnaires, to minimize recall bias. The breastfeeding log was filled out daily in the home and was not collected by the investigators.

\section{Variables and definitions}

Ip and colleagues ${ }^{46}$ highlighted the need for clear definitions in breastfeeding studies. We defined breastfeeding as infant feeding directly from the breast, in physical contact with the mother. We defined our study exposure variable, breastfeeding difficulty, as a self-reported "severe" or "unbearable" problem(s) on the Breastfeeding Experiences Scale ${ }^{47}$ and/or a score of less than 80 on the Maternal Breastfeeding Evaluation Scale. ${ }^{48}$ This combination of tools captures both maternal and infant difficulties in the physical and emotional domains. The primary outcome was postpartum depression, defined as a score of 10 or greater on the Edinburgh Postnatal Depression Scale $\mathrm{e}^{49-52}$ or a self-reported diagnosis of postpartum depression by a health care professional. We chose the Edinburgh Postnatal Depression Scale because of its international use in postpartum depression studies, its high validity and reliability in the Canadian population, and its ability to discriminate between postpartum blues (mild depressive symptoms that last $<1$ week) and postpartum depressive episodes. ${ }^{38,49-52}$ The Diagnostic and Statistical Manual of Mental Disorders, 5th edition (DSM-5), classifies postpartum depression as a major depressive episode with peripartum onset lasting at least 1 week.

\section{Analysis}

A comparison of key sample demographic characteristics with Calgarian, Albertan and Canadian averages showed that our sample is representative of Canadian breastfeeding women..$^{53,54}$ The data for participants with a positive result of screening for depression when their baby was born were excluded from the primary analysis to ensure the time sequence between breastfeeding difficulties and postpartum depression could be established and to avoid misclassification bias. We converged the qualitative results with the primary quantitative analysis by deriving a binary "negative breastfeeding support experience (Yes/ No)" variable from the qualitative themes. We then assessed this variable as a potential effect modifier/confounder in the primary analysis. Research assistants cleaned and verified all the data and confirmed or corrected outlying values, as appropriate, by contacting the participant. We treated missing values using case-wise deletion. All statistical analyses were completed with the use of STATA, version 9.0. We conducted logistic regression analysis, using a reverse elimination method wherein the maximum number of variables is included in the initial model, which is then reduced by successively removing variables that have no significant modifying or confounding effect. ${ }^{55}$ The final model contains only variables that are significant or that significantly modify or confound, in addition to the exposure variable and the outcome of interest. ${ }^{56} \mathrm{We}$ included variables in the model as potential confounders when associations with both breastfeeding difficulties and postpartum depression were observed, based on a combination of Z-tests for significant difference at $\alpha=0.05$ and scientific judgment.

\section{Results}

A total of 442 women agreed to participate and completed at least 1 questionnaire; 380 participants completed all 3 questionnaires (retention rate $86.0 \%$ ) (Figure 1). On recruitment, 88 
women $(19.9 \%)$ had a positive result of screening for depression, and their data were excluded from the primary analysis. The primary analysis thus included data for 354 women.

Maternal sociodemographic and clinical characteristics are summarized in Table 1. Most women (335 [79\%]) were aged 20-35, and about half (206 [49\%]) were parity 1 .

The sample was generally representative of the Calgary regional population (Figure 2). Birth characteristics did not deviate from a normal distribution and reflected expected values for the sample given the study selection criteria $^{56}$ (Table 2).

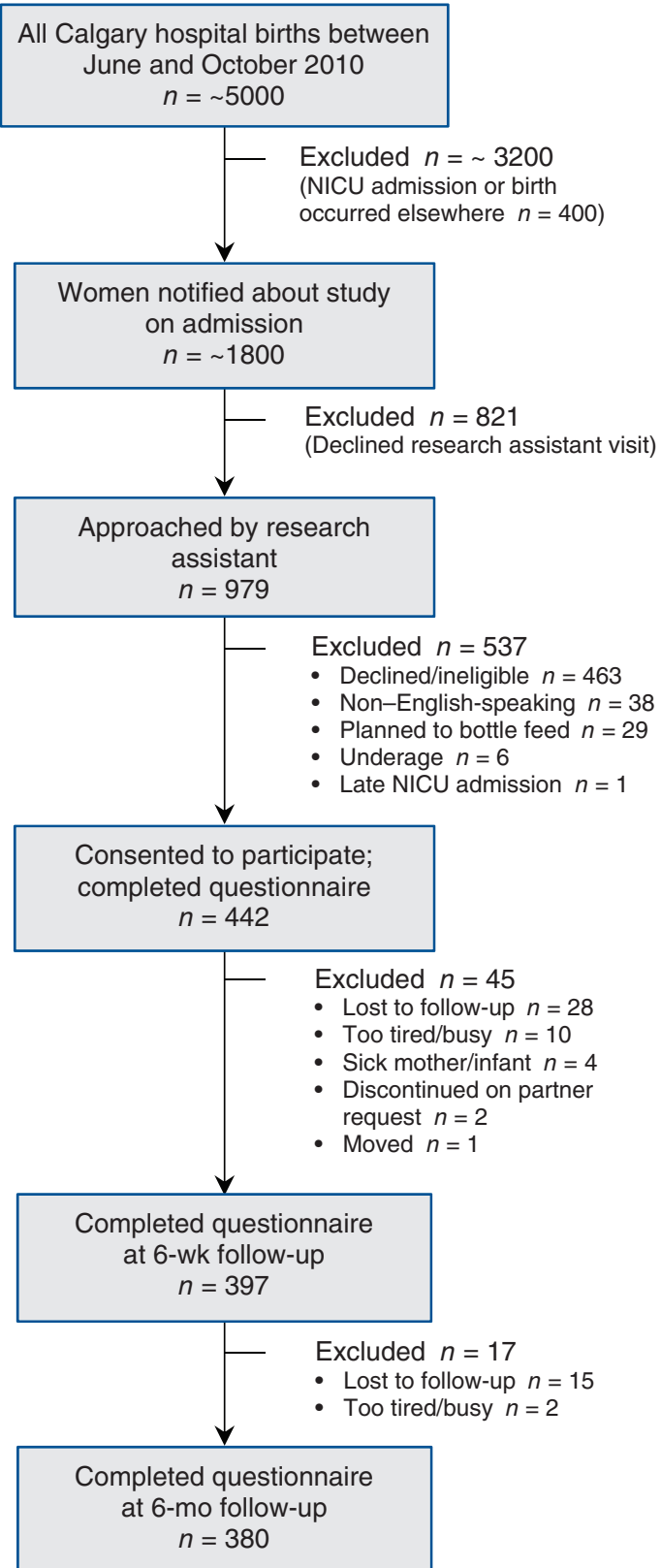

Figure 1: Flow diagram of the selection of study participants. $\mathrm{NICU}=$ neonatal intensive care unit.

\section{Exposure}

Overall, 386 women (87.3\%) experienced breastfeeding difficulties. Nearly all participants (437 [98.9\%]) reported receiving some form of advice, help or support for breastfeeding, some of which was unsolicited. Narrative on the quality of breastfeeding support experiences was provided by $332(75 \%)$ participants, and $17.7 \%(n=58)$ had one or more negative experiences.

\section{Outcome}

The prevalence rates of postpartum depression at 6 weeks and 6 months were $13.7 \%(n=54)$ and $14.9 \%(n=54)$ respectively.

The following variables were independently associated with breastfeeding difficulties and postpartum depression and had the potential to confound the primary analysis: body mass index (BMI), parity, low socioeconomic status (defined as 2 or

\begin{tabular}{|c|c|}
\hline \multicolumn{2}{|c|}{$\begin{array}{l}\text { Table 1: Maternal sociodemographic and clinical } \\
\text { characteristics }\end{array}$} \\
\hline Characteristic & $\begin{array}{l}\text { No. }(\%) \\
n=424\end{array}$ \\
\hline \multicolumn{2}{|l|}{ Age at delivery, yr } \\
\hline$>35$ & $85(20.0)$ \\
\hline $20-35$ & $335(79.0)$ \\
\hline$<20$ & $4(0.9)$ \\
\hline \multicolumn{2}{|l|}{ Education } \\
\hline High school or less & $54(12.7)$ \\
\hline At least some postsecondary & $370(87.3)$ \\
\hline Married/common-law relationship $(n=409)$ & $399(97.6)$ \\
\hline \multicolumn{2}{|l|}{ Annual household income, $\$(n=401)$} \\
\hline$>99000$ & $184(45.9)$ \\
\hline $40000-99000$ & $166(41.4)$ \\
\hline$<40000$ & $51(12.7)$ \\
\hline Owns home $(n=413)$ & $301(72.9)$ \\
\hline \multicolumn{2}{|l|}{ Primary language at home $(n=414)$} \\
\hline English & $356(86.0)$ \\
\hline Other & $58(14.0)$ \\
\hline Living in Canada $<5 \mathrm{yr}$ & $25(6.0)$ \\
\hline \multicolumn{2}{|l|}{ BMI (prepregnancy) $(n=81)$} \\
\hline$<18.5$ & $4(4.9)$ \\
\hline $18.5-25$ & $44(54.3)$ \\
\hline$>25$ & $33(40.7)$ \\
\hline \multicolumn{2}{|l|}{ Parity $(n=420)$} \\
\hline 1 & $206(49.0)$ \\
\hline$>1$ & $214(51.0)$ \\
\hline Planned pregnancy $(n=419)$ & $319(76.1)$ \\
\hline Cesarean delivery $(n=423)$ & $157(37.1)$ \\
\hline Depressed at delivery & $88(19.9)$ \\
\hline
\end{tabular}


more of annual household income $<\$ 60$ 000, maternal education high school or less, residing in Canada $<5 \mathrm{yr}$, marital status single/divorced/separated or no partner, not owning one's home and primary language not English), unplanned pregnancy and cesarean delivery. There were insufficient numbers of participants to enable analysis for confounding by BMI and socioeconomic status. Potential confounders did not demonstrate confounding effects on the relationship between breastfeeding difficulties and postpartum depression (Table 3).

In the final regression model a negative breastfeeding support experience was a significant effect modifier of the relationship between breastfeeding difficulties and postpartum depression $(p=0.02)$. Women who had a negative breastfeeding support experience(s) in addition to breastfeeding difficulties showed no increased risk of postpartum depression in the first 6 months following delivery compared with those who had no breastfeeding difficulties (risk ratio [RR] 3.1, 95\% confidence interval [CI] 0.93-18.22). However, women who experienced breastfeeding difficulties and did not report a negative support experience had a decreased risk of postpartum depression (RR 0.35, 95\% CI 0.16-0.77), translating to a 6-month risk of postpartum depression of $5.25 \%$ (Table 4).

\section{Interpretation}

In this prospective mixed-methods cohort study involving women who were free from depression at study intake, we found that breastfeeding difficulties were prevalent and that almost all participants received some form of help, advice or support for breastfeeding, some of which was unsolicited. Their experience with breastfeeding support significantly modified the primary association between breastfeeding diffi- culties and postpartum depression, creating 2 distinct groups with different levels of quantified risk. We observed a significant decrease in the risk of postpartum depression among women with breastfeeding difficulties who did not have a negative breastfeeding support experience(s). Among women who had a negative breastfeeding support experience(s), those with breastfeeding difficulties showed no increased risk of postpartum depression in the first 6 months following delivery compared with those who had no breastfeeding difficulties.

The prevalence of postpartum depression observed in our study, $14 \%-15 \%$, is in line with current published international and national prevalence estimates, which range from $7 \%$ to $15 \%$ with the use of various screening tools. ${ }^{62-64}$ The reduced risk among women who did not have a negative breastfeeding support experience(s) was congruent with the study hypotheses and is in keeping with the literature on risk of postpartum depression. ${ }^{53,54}$ Poor satisfaction with social supports and low perceived partner support are known risk factors for postpartum depression, whereas positive social support interventions have shown effectiveness in the treatment of the condition. ${ }^{53,54}$

The observed protective effect of breastfeeding difficulties with respect to postpartum depression may seem counterintuitive, as it suggests that breastfeeding difficulties have a positive effect on maternal mental health. However, the observed protective effect is likely due to the fact that women who are having breastfeeding difficulties are more likely to receive more support than those who have no difficulties. As long as the support is not perceived as negative, it not only aids with breastfeeding but also reduces the risk of postpartum depression. That is, positive support interactions early in the postpartum period seem to have a positive effect on maternal

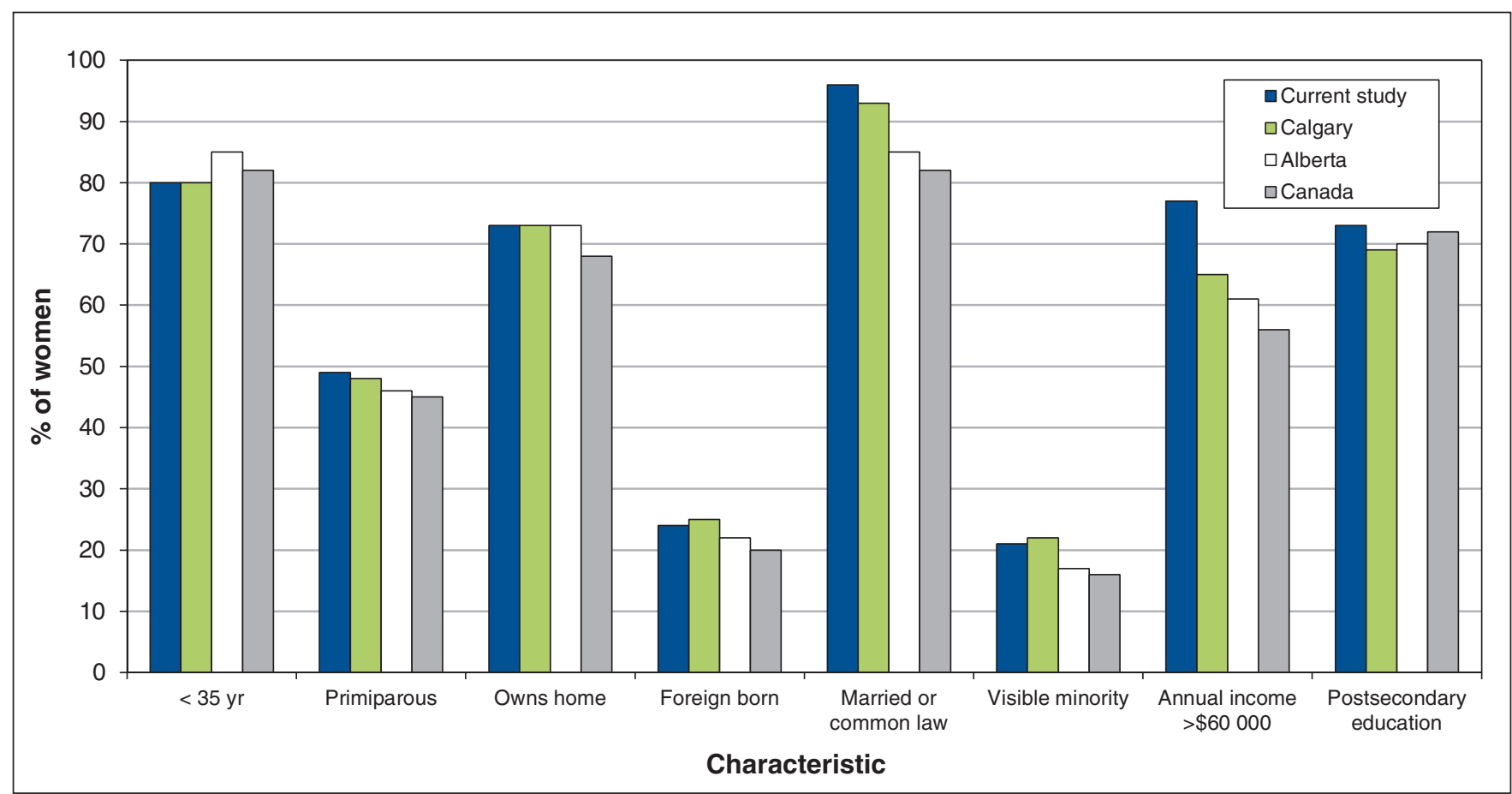

Figure 2: Comparison of study sample maternal characteristics to population averages in Calgary, in Alberta and in Canada. ${ }^{57-61}$ 
mental health. Our observations of the preventive nature of support (provided it is not negative) align with findings from previous studies that showed the effectiveness of socialsupport interventions such as "listening visits" in the United Kingdom and a telephone-based peer-support program tested in Canada for the prevention of postpartum depression at 12 weeks post partum. . $^{54,64,65}$

Whereas previous investigators have been able to establish that women with postpartum depression are more likely than those without this condition to have breastfeeding problems and to cease breastfeeding earlier, our study was designed and powered to examine breastfeeding difficulties as an exposure that precedes postpartum depression. Our findings highlight a clinically meaningful interaction between breastfeeding difficulties, breastfeeding support experience and postpartum depression that provide insight to how the timing of breastfeeding problems and their supports are implicated in risk of postpartum depression. Our findings also identify breastfeeding support as an important potential intervention to prevent postpartum depression. The prevalence of this condition has remained consistent over the last decade or more, which indi-

\begin{tabular}{|lcc|}
\hline \multicolumn{2}{l}{ Table 2: Selected birth characteristics } \\
\hline Characteristic & Mean \pm SD & Range \\
\hline Maternal age at delivery, yr & $\begin{array}{c}31.4 \pm 5.1 \\
n=424\end{array}$ & $18-46$ \\
& $\begin{array}{c}39.1 \pm 1.3 \\
n=423\end{array}$ & $36-42$ \\
\hline Gestational age, wk & $\begin{array}{c}3263 \pm 493.0 \\
n=422\end{array}$ & $2268-4610$ \\
\hline Birth weight, g & & \\
\end{tabular}

Table 3: Results of analysis for potential confounding

\begin{tabular}{|lc|}
\hline Variable & Adjusted RR $(95 \% \mathrm{Cl})$ \\
\hline Parity & $0.78(0.405-1.487)$ \\
\hline Cesarean delivery & $0.75(0.393-1.434)$ \\
\hline Unplanned pregnancy & $0.69(0.363-1.302)$ \\
\hline Unadjusted & $0.75(0.392-1.433)$ \\
\hline Note: $\mathrm{Cl}=$ confidence interval, RR = risk ratio. & \\
\hline
\end{tabular}

Table 4: Risk ratios for postpartum depression with exposure to breastfeeding difficulties, stratified on negative breastfeeding support experience(s) (no confounding)

\begin{tabular}{lc}
$\begin{array}{l}\text { Had negative breastfeeding support } \\
\text { experience(s) }\end{array}$ & $\mathrm{RR}(95 \% \mathrm{Cl})$ \\
\hline Yes & $3.11(0.93-18.22)$ \\
\hline No & $0.35(0.16-0.77)$ \\
\hline Crude (unadjusted) & $0.750(0.39-1.43)$ \\
\hline Pooled (Mantel-Haenszel combined) & $0.068(0.35-1.33)$ \\
\hline
\end{tabular}

cates that current interventions are not reaching the population of women at risk or are ineffective. . $^{34,37,38,63,64}$ Existing networks of professional and community-based breastfeeding support, which are commonly in close contact with breastfeeding women, are ideal settings for education programs to optimize postpartum care and increase efforts to prevent postpartum depression. Partner education during prenatal classes could include delineation of the importance of positive breastfeeding support and what it entails.

\section{Strengths and limitations}

One study limitation is that we were unable to perform diagnostic interviews for depression, for feasibility reasons. Although highly validated, our outcome measure (the Edinburgh Postnatal Depression Scale) is only able to measure depressive symptoms, and, thus, some misclassification may have occurred. However, any misclassification would have been nondifferential (i.e., would have occurred equally among the exposed and nonexposed) and would thus bias the overall result toward the null. The Edinburgh Postnatal Depression Scale has been widely validated as a highly sensitive and specific tool for the measurement of postpartum depression and, in fact, may be more accurate than the DSM-5 classification. Thus, we estimate that the effect of misclassification in this study, if any, was very small and does not affect the interpretation of the findings.

As with any prospective cohort study, selection bias due to differential discontinuation by participants may threaten validity. Our study had low attrition, and the comparison of exposure status between participants and discontinuers $(87 \%$ v. $89 \%, p=0.5$ ) shows little potential for bias. Recall bias was mitigated through the use of a daily breastfeeding log, which the participants referred to when completing the follow-up questionnaires.

Our sample had a slightly higher rate of annual household income over $\$ 60000$ than the Calgary regional population $(77 \%$ v. $65 \%)$, likely owing to the inclusion of only breastfeeding women. Evidence suggests that breastfeeding rates are lower among women from lower income brackets. ${ }^{46}$

Our relatively small sample size led to wide confidence intervals. The number of women who did not experience breastfeeding difficulty was especially small. Larger studies on this topic would be prudent to obtain more precise effect estimates.

Our study examined breastfeeding difficulties as the primary exposure, yielding novel results that complement the existing literature on the link between breastfeeding and postpartum depression.

Our use of mixed methods increased the validity of the variable "breastfeeding support experience" compared with a categorical question, which can be heavily biased by investigator assumption and thus not reflect the true maternal experience. We have shown under what circumstances protective effects occur in the breastfeeding-postpartum depression relationship, and our qualitative data ${ }^{44}$ provide detailed information about the way services can be improved to potentially prevent postpartum depression. 


\section{Conclusion}

Breastfeeding experiences and their associated supports are important factors in postpartum mental health. The development and implementation of novel interventions that adapt the way in which breastfeeding support is delivered can likely reduce the incidence of postpartum depression in Canada.

\section{References}

1. Postpartum care of the mother and newborn: a practical guide. Geneva: World Health Organization, Department of Reproductive Health and Research (RHR); 1998. Available: http://apps.who.int/iris/bitstream/10665/66439/1/ WHO_RHT_MSM_98.3.pdf (accessed 2015 Sept. 8).

2. Istre GR, Conner J, Broome CV, et al. Risk factors for primary invasive Haemophilus influenzae disease: increased risk from day care attendance and school aged household members. 7 Pediatr 1985;106:190-5.

3. Cochi SL, Fleming DW, Hightower A, et al. Primary invasive Haemophilus influenzae type b disease: a population-based assessment of risk factors. 7 Pediatr 1986;108:887-96.

4. Dewey KG, Heinig MJ, Nommsen-Rivers L. Differences in morbidity between breast-fed and formula-fed infants. 7 Pediatr 1995;126:696-702.

5. Howie PW, Forsyth J, Ogston S, et al. Protective effect of breast feeding against infection. BMF 1990;300:11-6.

6. Kramer MS, Guo T, Platt RW, et al. Infant growth and health outcomes associated with 3 compared with 6 mo of exclusive breastfeeding. Am 7 Clin Nutr 2003;78:291-5

7. Popkin BM, Adair L, Akin J, et al. Breastfeeding and diarrheal morbidity. Pediatrics 1990;86:874-82.

8. Beaudry M, Dufour R, Marcoux S. Relation between infant feeding and infections during the first six months of life. F Pediatr 1995;126:191-7.

9. Bhandari N, Bahl R, Mazumdar S, et al. Effect of community-based promotion of exclusive breastfeeding on diarrhoeal illness and growth: a cluster randomised controlled trial. Infant Feeding Study Group. Lancet 2003;361:1418-23.

10. López-Alarcón M, Villalpando S, Fajardo A. Breast-feeding lowers the frequency and duration of acute respiratory infection and diarrhea in infants under six months of age. 7 Nutr 1997;127:436-43.

11. Blaymore Bier JA, Oliver T, Ferguson A, et al. Human milk reduces outpatient upper respiratory symptoms in premature infants during their first year of life. 7 Perinatol 2002;22:354-9.

12. Bachrach VR, Schwarz E, Bachrach L. Breastfeeding and the risk of hospitalization for respiratory disease in infancy: a meta-analysis. Arch Pediatr Adolesc Med 2003; 157:237-43.

13. Chulada PC, Abres S, Dunson D, et al. Breast-feeding and the prevalence of asthma and wheeze in children: analyses from the Third National Health and Nutrition Examination Survey, 1988-1994. F Allergy Clin Immunol 2003;111: 328-36.

14. Oddy WH, Peat J, de Klerk N. Maternal asthma, infant feeding, and the risk of asthma in childhood. 7 Alleroy Clin Immunol 2002;110:65-7.

15. Gdalevich M, Mimouni D, Mimouni M. Breast-feeding and the risk of bronchial asthma in childhood: a systematic review with meta-analysis of prospective studies. 7 Pediatr 2001;139:261-6.

16. Oddy WH, Holt PG, Sly PD. Association between breast feeding and asthma in 6-year-old children: findings of a prospective birth cohort study. BMF 1999;319:815-9.

17. Ramos L, Eljarrat E, Hernández LM, et al. Levels of PCDDs and PCDFs in farm cow's milk located near potential contaminant sources in Asturias (Spain). Comparison with levels found in control, rural farms and commercial pasteurized cow's milks. Chemosphere 1997;35:2167-79.

18. Saarinen UM. Prolonged breastfeeding as prophylaxis for recurrent otitis media. Acta Paediatr Scand 1982;71:567-71.

19. Duncan B, Holberg C, Wright A, et al. Exclusive breastfeeding for at least 4 months protects against otitis media. Pediatrics 1993;91:867-72.

20. Owen MJ, Baldwin CD, Swank PR, et al. Relation of infant feeding practices, cigarette smoke exposure, and group child care to the onset and duration of otitis media with effusion in the first two years of life. F Pediatr 1993;123:702-11.

21. Paradise JL, Elster B, Tan L. Evidence in infants with cleft palate that breast milk protects against otitis media. Pediatrics 1994;94:853-60.

22. Aniansson G, Alm B, Andersson B, et al. A prospective cohort study on breastfeeding and otitis media in Swedish infants. Pediatr Infect Dis 7 1994;13: $183-8$

23. Pisacane A, Continisio GI, Aldinucci M, et al. A controlled trial of the father's role in breastfeeding promotion. Pediatrics 2005;116:e494-8

24. Mårild S, Hansson S, Jodal U, et al. Protective effect of breastfeeding against urinary tract infection. Acta Paediatr 2004:93:164-8.

25. Schanler MA, Strobino DM, Lau C. Feeding strategies for premature infants: beneficial outcomes of feeding fortified human milk versus preterm formula. Pediatrics 1999;103:1150-7.

26. Li R, Jewell S, Grummer-Strawn L. Maternal obesity and breastfeeding practices. Am 7 Clin Nutr 2003;77:931-6.
27. Davanzo R, Bruno I. Breastfeeding and women's health. Med Bambino 2003 22:105-13.

28. Shaw-Flach A. Management of common breastfeeding problems. Comm Pract 2002; $75: 432-5$.

29. Dewey KG, Nommsen-Rivers L, Heinig MJ, et al. Risk factors for suboptima infant breastfeeding behavior, delayed onset of lactation, and excess neonatal weight loss. Pediatrics 2003;112:607-19.

30. Chalmers B, Levitt C, Heaman M, et al.; Maternity Experiences Study Group of the Canadian Perinatal Surveillance System, Public Health Agency of Canada. Breastfeeding rates and hospital breastfeeding practices in Canada: a national survey of women. Birth 2009;36:122-32.

31. Yang Q, Wen S, Dubois L, et al. Determinants of breastfeeding and weaning in Alberta, Canada. 7 Obstet Gynaecol Can 2004;26:975-81.

32. Kehler HL, Chaput K, Tough SC. Risk factors for cessation of breastfeeding prior to six months of age among a community sample of women in Calgary, Alberta. Can 7 Public Health 2009;100:376-80.

33. Hauck YL, Irurita VF. Constructing compatibility: managing breast-feeding and weaning from the mother's perspective. Qual Health Res 2002;12:897-914.

34. Buttner MM, O'Hara MW, Watson D. The structure of women's mood in the early postpartum. Assessment 2012;19:247-56.

35. Acceptable medical reasons for the use of breast-milk substitutes. Geneva: World Health Organization; 2009. Available: http://whqlibdoc.who.int/hq/2009/ WHO_FCH_CAH_09.01_eng.pdf (accessed 2012 Sept. 14)

36. Knaak S. Breast-feeding, bottle-feeding and Dr. Spock: the shifting context of choice. Can Rev Sociol Anthropol 2005;42:197-216.

37. Murray L, Fiori-Cowley A, Hooper R, et al. The impact of postnatal depression and associated adversity on early mother-infant interactions and later infant outcome. Child Dev 1996;67:2512-26.

38. O'Hara MW. Postpartum depression: what we know. 7 Clin Psychol 2009;65: 1258-69.

39. Cantwell R, Cox JL. Psychiatric disorders in pregnancy and the puerperium. Curr Obstet Gynaecol 2006;16:14-20.

40. Kendell RE, Chalmers J, Platz C. Epidemiology of puerperal psychosis. $\mathrm{Br} \mathcal{F}$ Psychiatry 1987;150:662-73.

41. O'Connor TG, Heron JPD, Glover VPD; Alspac Study Team. Antenatal anxiety predicts child behavioral/emotional problems independently of postnatal depression. 7 Am Acad Child Adolesc Psychiatry 2002;41:1470-7.

42. Van den Bergh BR, Mulder EJ, Mennes M, et al. Antenatal maternal anxiety and stress and the neurobehavioural development of the fetus and child: links and possible mechanisms. A review. Neurosci Biobehav Rev 2005;29:237-58.

43. O'Connor TG, Heron J, Golding J, et al. Maternal antenatal anxiety and behavioural/emotional problems in children: a test of a programming hypothesis. 7 Child Psychol Psychiatry 2003;44:1025-36.

44. Chaput KH, Adair CE, Nettel-Aguirre A, et al. The experience of nursing women with breastfeeding support: a qualitative inquiry. CMA7 Open 2015;3:E305-9.

45. Bland RM, Rollins NC, Solarsh G, et al. Maternal recall of exclusive breast feeding duration. Arch Dis Child 2003;88:778-83.

46. Ip S, Chung M, Raman G, et al. Breastfeeding and maternal and infant bealth out comes in developed countries. Evidence Report/Technology Assessment no. 153 [prepared by Tufts-New England Medical Center Evidence-based Practice Center under contract no. 290-02-0022]. AHRQ publication no. 07-E007. Rockville (MD): Agency for Healthcare Research and Quality; 2007.

47. Riordan JM, Woodley G, Heaton K. Testing validity and reliability of an instrument which measures maternal evaluation of breastfeeding. 7 Hum Lact 1994;10:231-5.

48. Leff EW, Jefferis SC, Gagne MP. The development of the Maternal Breastfeeding Evaluation Scale. 7 Hum Lact 1994;10:105-11.

49. Cox JL, Holden J, Sagovsky R. Detection of postnatal depression: development of the 10 item Edinburgh Postnatal Depression Scale. Br F Psychiatry 1987;150:782-6.

50. Cox JL, Chapman G, Murray D, et al. Validation of the Edinburgh Postnata Depression Scale (EPDS) in non-postnatal women. 7 Affect Disord 1996;39:185-9.

51. Jardri R, Pelta J, Maron M, et al. Predictive validation study of the Edinburgh Postnatal Depression Scale in the first week after delivery and risk analysis for postnatal depression. 7 Affect Disord 2006;93:169-76.

52. Matthey S, Henshaw C, Elliott B. Variability in the use of cut-off scores and formats on the Edinburgh Postnatal Depression Scale: implications for clinical and research practice. Arch Womens Ment Health 2006;9:309-15.

53. McDonald S, Wall J, Jack M, et al. Development of a psychosocial prenata screening tool for suboptimal mental health in the postpartum period. Paediatr Perinat Epidemiol 2012;26:316-27.

54. Dennis CL. Psychosocial and psychological interventions for prevention of postnatal depression: systematic review. BM7 2005;331:15

55. Rothman K, Greenland S, Lash T. Modern epidemiology. 3rd ed. Philadelphia: Lippincott Williams \& Wilkins; 2008:258-82.

56. Breslow NE, Day NE. The analysis of case-control studies. vol 1 of Statistical methods in cancer research series. 8th ed. IARC Scientific Publications no. 32. Lyon: International Agency for Research on Cancer; 2000.

57. McDonald SW, Lyon AW, Benzies KM, et al. The All Our Babies pregnancy cohort: design, methods, and participant characteristics. BMC Pregnancy Childbirth 2013;13(Suppl 1):S2.

58. What mothers say: the Canadian Maternity Experiences survey. Ottawa: Public Health Agency of Canada; 2009. 
59. Data tables: the Maternity Experiences Survey (MES) 2006-2007. Ottawa: Public Health Agency of Canada; 2009. Available: www.phac-aspc.gc.ca/rhsssg/pdf/tab-eng.pdf (accessed 2012 Nov. 30).

60. Couple families by presence of children of all ages in private households, 2006 counts, for Canada, provinces and territories, and census metropolitan areas and census agglomerations - 20\% sample data. Ottawa: Statistics Canada. Available: www12.statcan.gc.ca/census-recensement/2006/dp-pd/hlt/97-553/pages/ page.cfm? Lang $=\mathrm{E} \& \mathrm{Geo}=\mathrm{CMA} \&$ Code $=48 \&$ Table $=1 \&$ Data $=$ Count $\&$ Age $=1 \&$ StartRec $=1 \&$ Sort $=7 \&$ Display=Page $\&$ CSDFilter $=5000$ (accessed 2015 Jan. 19).

61. 2006 community profiles. Ottawa: Statistics Canada; 2007. Available: www12. statcan.ca/census-recensement/2006/dp-pd/prof/92-591/index.cfm?Lang=E (accessed 2012 Mar. 19).

62. O'Hara M, Swain A. Rates and risk of postpartum depression - a metaanalysis. Int Rev Psychiatry 1996;8:37-54.

63. Dennis CL, Heaman M, Vigod S. Epidemiology of postpartum depressive symptoms among Canadian women: regional and national results from a crosssectional survey. Can 7 Psychiatry 2012;57:537-46.

64. Gavin NI, Gaynes BN, Lohr KN, et al. Perinatal depression: a systematic review of prevalence and incidence. Obstet Gynecol 2005;106:1071-83.

65. Dennis CL, Hodnett ED. Psychosocial and psychological interventions for treating postpartum depression. Cochrane Database Syst Rev 2007;(4):CD006116.
Affiliations: Department of Community Health Sciences (Chaput, Nettel-Aguirre, Musto, Adair, Tough), Cumming School of Medicine; Department of Paediatrics (Chaput, Nettel-Aguirre, Tough), Cumming School of Medicine, University of Calgary; Alberta Health Services Calgary Zone (Musto); Department of Psychiatry (Adair), Cumming School of Medicine, University of Calgary, Calgary, Alta.

Contributors: All authors contributed to the concept and design of the study. Kathleen Chaput acquired the data, and Kathleen Chaput, Alberto Nettel-Aguirre, Carol Adair and Suzanne Tough were involved in the analysis and interpretation of the data. Kathleen Chaput drafted the article, and Alberto Nettel-Aguirre, Richard Musto, Carol Adair and Suzanne Tough critically revised the manuscript for intellectual content, gave final approval of the version to be published and agreed to act as guarantors of the work.

Supplemental information: For reviewer comments and the original submission of this manuscript, please see www.cmajopen.ca/content/4/1/ E103/suppl/DC1 